Check for updates

Cite this: RSC Adv., 2017, 7, 42513

Received 10th August 2017

Accepted 27th August 2017

DOI: 10.1039/c7ra08865e

rsc.li/rsc-advances

\section{Cucurbit[7]uril complexations of Good's buffers $\uparrow$}

\begin{abstract}
Allison J. Selinger and Donal H. Macartney
The cucurbit[7]uril (CB[7]) host-guest complexations of a series of zwitterionic "Good's" biological pH buffers have been investigated in aqueous solution by means of ${ }^{1} \mathrm{H}$ NMR spectroscopy. The cyclohexylammonium buffers bind very strongly $\left(K_{\mathrm{CB}[7]}=10^{7}\right.$ to $\left.10^{8} \mathrm{dm}^{3} \mathrm{~mol}^{-1}\right)$, while the morpholinium $\left(10^{2}\right.$ to $\left.10^{3} \mathrm{dm}^{3} \mathrm{~mol}^{-1}\right)$ and piperazinium $\left(10^{3}\right.$ to $\left.10^{4} \mathrm{dm}^{3} \mathrm{~mol}^{-1}\right)$ buffers have binding constants several orders of magnitude smaller. The binding constants increase as the distance between the ammonium and sulfonate groups increases. The $\mathrm{p} K_{\mathrm{a}}$ of 2-(cyclohexylammonio)ethanesulfonate (CHES) increases by 3.1 units upon complexation by $\mathrm{CB}$ [7].
\end{abstract}

\section{Introduction}

In 1966, N. E. Good proposed criteria for an optimum biological buffer, ${ }^{1}$ and his group ${ }^{2,3}$ and others ${ }^{4}$ reported the syntheses of several series of zwitterionic compounds (Fig. 1) which are now standard buffers employed in biochemistry. The criteria included easy synthetic preparation (with a resistance to degradation), $\mathrm{p} K_{\mathrm{a}}$ values between 6 and 8 (with a minimal dependence on temperature, concentration, or ionic strength), water solubility, impermeability to biological membranes, and a lack of binding to other biological cations. The majority of the Good's buffers bear sulfonate groups, which are anionic at physiological $\mathrm{pH}$ and enhance the water solubility of the buffer, and tertiary amine groups, whose protonated forms have $\mathrm{p} K_{\mathrm{a}}$ values near to or above 7 .

As a result of their zwitterionic nature, the Good's buffers have recently been used as the anionic or cationic components of ionic liquids (GBILs), for use as self-buffering and biocompatible media for protein and antibody extractions. ${ }^{5-10}$ The Good's buffers have also been employed to stabilize platinum and gold nanoparticles, affecting their structures and optical properties. ${ }^{11-16}$

Despite the proposed criteria, a number of the buffers result in metal ion depletion (notably copper) ${ }^{17-23}$ and interactions with biological systems, leading to unwanted or beneficial physiological effects. ${ }^{\mathbf{2 4 , 2 5}}$ The former problem has been remedied to some degree by "Better" $\mathrm{pH}$ buffers such as PIPES (Fig. 1), which are non-complexing towards metal ions. ${ }^{26,27}$ There has, however, been little in the way of studies on the interactions of these $\mathrm{pH}$ buffers with macrocyclic host molecules, ${ }^{28-30}$ such as cyclodextrins, calixarenes, and cucurbiturils,

Department of Chemistry, Queen's University, Kingston, ON K7L 3N6, Canada. E-mail: dhm@queensu.ca

$\dagger$ Electronic supplementary information (ESI) available: ${ }^{1} \mathrm{H}$ NMR spectra of guest and host-guest complexes, ${ }^{1} \mathrm{H}$ NMR titration plots, and limiting chemical shift values. See DOI: 10.1039/c7ra08865e which are of increasing interest in biological, biochemical, and medicinal applications. ${ }^{31-34}$

In this study, the host-guest complexations of a series of Good's (and related) pH buffers (Fig. 1) by the macrocyclic host molecule cucurbit[7]uril (CB[7]) have been studied using ${ }^{1} \mathrm{H}$ NMR spectroscopy. The cucurbit $[n]$ urils $(\mathrm{CB}[n], n=5-8,10$ and

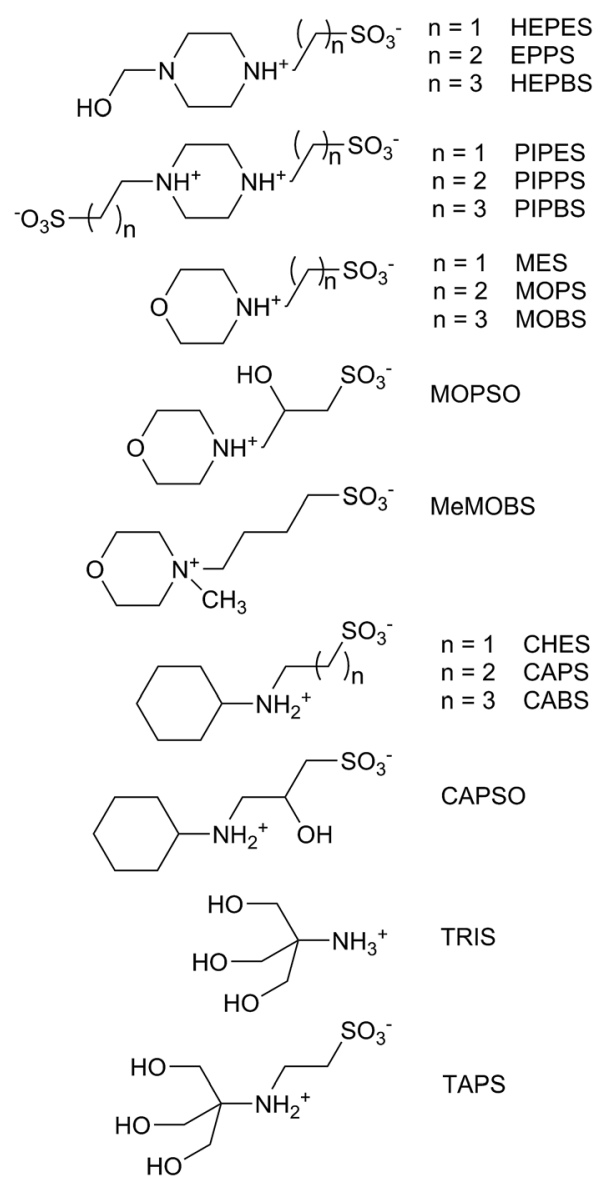

Fig. 1 Good's type biological pH buffers used in this study. 
13-15) are a family of host molecules comprised of cyclic oligomers of $n$ glycoluril units bridged by $2 n$ methylene groups. ${ }^{34-36}$ The $\mathrm{CB}[n]$ hosts form very stable $\left(K_{\mathrm{CB}[n]} \text { up to } 10^{17} \mathrm{dm}^{3} \mathrm{~mol}^{-1}\right)^{37}$ host-guest complexes with organic cations in aqueous solution, utilizing dipole-dipole and ion-dipole interactions at the polar portals and hydrophobic interaction in the cavity. One feature of the binding of basic organic guests is the preferred complexation of their conjugate acid, resulting in an increase in the $\mathrm{p} K_{\mathrm{a}}$ value. ${ }^{38-41}$

Cucurbiturils have recently gained interest in biological, biochemical and medicinal applications, as studies have suggested little evidence of toxicity. ${ }^{\mathbf{4 2 - 4 5}}$ For $\mathrm{pH}$ control in these cucurbituril host-guest studies, acetate and phosphate buffers are most commonly used, although TRIS (tris(hydroxymethyl) methylamine) has been used in a few instances, ${ }^{\mathbf{4 6 - 4 9}}$ including early studies of $\mathrm{CB}[7]$ with the methyl viologen dication $\left(\mathrm{MV}^{2+}\right){ }^{46,47}$ Ong and Kaifer ${ }^{47}$ noted that binding constant for $\mathrm{MV}^{2+}$, measured in $30 \mathrm{mmol} \mathrm{\textrm {dm } ^ { - 3 }}$ TRIS, was about $10 \%$ higher than previously reported in $50 \mathrm{mmol} \mathrm{\textrm {dm } ^ { - 3 }} \mathrm{TRIS}^{45}$ and suggested that the buffer can compete for the host, as found for alkali metal and alkali earth cations. ${ }^{50-52}$

The cucurbit[7]uril complexations of the four series of Good's buffers, based on cyclohexylammonium, piperazinium, $N$-2-hydroxyethylpiperazinium, morpholinium, and tris(hydroxymethyl)methylammonium, with alkanesulfonate group substituents, have been investigated using ${ }^{1} \mathrm{H}$ NMR spectroscopy. The host-guest stability constants and the complexation induced guest proton chemical shift values have been determined and related to the nature of cationic portion of the buffer and the length of the alkane chain separating it from the sulfonate group(s). The effect of $\mathrm{CB}$ [7] complexation of CHES on its $\mathrm{p} K_{\mathrm{a}}$ value is also reported.

\section{Experimental}

\section{Materials}

The cucurbit[7]uril was prepared and characterized by the method of Day et al. ${ }^{53}$ The majority of the buffers were used as received (Sigma-Aldrich or GFS Chemicals (for PIPPS)). The MOBS, MeMOBS and CABS compounds were prepared by the method of Yi et al., ${ }^{54}$ employing 1,4-butane sultone with morpholine, $N$-methylmorpholine, or cyclohexylamine, respectively. The PIPBS buffer was prepared as described by Jermyn. ${ }^{55}$

MOBS. $60 \%$ yield. ${ }^{1} \mathrm{H}$ NMR $\left(300 \mathrm{MHz}, \mathrm{D}_{2} \mathrm{O}\right) \delta 4.01(\mathrm{br}, 2 \mathrm{H})$, 3.75 (br, 2H), 3.44 (br, 2H), 3.14 (t, 2H, $J=7.3$ ppm, overlapping br peak, 2H), 2.88 (t, 2H, $7.3 \mathrm{~Hz}), 1.90-1.65(\mathrm{~m}, 6 \mathrm{H}) \mathrm{ppm} .{ }^{13} \mathrm{C}$ NMR (75 MHz, $\left.\mathrm{D}_{2} \mathrm{O}\right) \delta 63.85,56.55,51.60,49.95,21.92$, 21.19 ppm.

MeMOBS. $43 \%$ yield. ${ }^{1} \mathrm{H}$ NMR $\left(300 \mathrm{MHz}, \mathrm{D}_{2} \mathrm{O}\right) \delta 3.97(\mathrm{br}, 4 \mathrm{H})$, $3.42(\mathrm{~m}, 8 \mathrm{H}), 3.11(\mathrm{~s}, 3 \mathrm{H}), 2.90(\mathrm{t}, 2 \mathrm{H}, J=7.5 \mathrm{~Hz}), 1.88(\mathrm{~m}, 2 \mathrm{H})$, 1.75 (qn, $2 \mathrm{H}, J=7.1 \mathrm{~Hz}$ ) ppm. ${ }^{13} \mathrm{C}$ NMR $\left(75 \mathrm{MHz}, \mathrm{D}_{2} \mathrm{O}\right) \delta 64.33$, 60.31, 59.59, 49.91, 46.79, 21.04, 19.85 ppm.

CABS. $48 \%$ yield. ${ }^{1} \mathrm{H}$ NMR $\left(300 \mathrm{MHz}, \mathrm{D}_{2} \mathrm{O}\right) \delta 3.00(\mathrm{~m}, 3 \mathrm{H})$, 2.87 (m, 2H), 1.98 (br, 2H), 1.74 (br, 2H), $1.73(\mathrm{~m}, 4 \mathrm{H}), 1.58$ (d, $=12.3 \mathrm{~Hz}, 1 \mathrm{H}), 1.23$ (qn, $J=12.3 \mathrm{~Hz}, 4 \mathrm{H}), 1.11(\mathrm{~m}, 1 \mathrm{H}) \mathrm{ppm} .{ }^{13} \mathrm{C}$ NMR (75 MHz, $\left.\mathrm{D}_{2} \mathrm{O}\right) \delta 57.09,50.07,43.78,28.86,24.62,23.89$, 21.33 ppm.
PIPBS. 58\% yield. ${ }^{1} \mathrm{H}$ NMR $\left(300 \mathrm{MHz}, \mathrm{D}_{2} \mathrm{O}\right) \delta 3.66(\mathrm{br}, 8 \mathrm{H})$, $3.25(\mathrm{t}, 4 \mathrm{H}, J=7.9 \mathrm{~Hz}), 2.87(\mathrm{t}, 4 \mathrm{H}, J=7.3 \mathrm{~Hz}), 1.86(\mathrm{qn}, 4 \mathrm{H}, J=$ $7.9 \mathrm{~Hz}$ ), 1.75 (qn, $4 \mathrm{H}, J=7.3 \mathrm{~Hz}$ ) ppm. ${ }^{13} \mathrm{C} \mathrm{NMR}\left(75 \mathrm{MHz}, \mathrm{D}_{2} \mathrm{O} /\right.$ DCl) $\delta 56.07,49.35,43.77,29.33,21.58$ ppm.

\section{Methods}

The 1D and 2D ${ }^{1} \mathrm{H}$ and ${ }^{13} \mathrm{C}$ NMR spectra were recorded on Bruker Avance 300 and 400 instruments. The host-guest binding constants were determined from ${ }^{1} \mathrm{H}$ NMR titrations or by ${ }^{1} \mathrm{H}$ NMR competitive binding experiments in $\mathrm{D}_{2} \mathrm{O}$ at $\mathrm{pD}=$ $4.75\left(0.050 \mathrm{~mol} \mathrm{dm}^{-3} \mathrm{NaOAc}-d_{3} / 0.025 \mathrm{~mol} \mathrm{dm}^{-3} \mathrm{DCl}\right)$. The competitor guest used was 3-(trimethylsilyl)propionic-2,2,3,3- $d_{4}$ acid (TSP), ${ }^{56}$ with a reported $\mathrm{CB}[7]$ binding constant of $(1.82 \pm$ $0.22) \times 10^{7} \mathrm{dm}^{3} \mathrm{~mol}^{-1}$. The stability constants for weaker $\mathrm{CB}[7]$ complexes were determined from either non-linear least squares fitting of ${ }^{1} \mathrm{H}$ NMR chemical shift titrations or from Benesi-Hildebrand plots $(1 / \Delta \delta$ vs. $1 / \mathrm{CB}[7]) .{ }^{57}$ For the PIPBS buffer, slow exchange behaviour is observed in the NMR titrations, and the value of $K_{\mathrm{CB}[7]}$ was calculated by integrating the free and bound methine proton resonances of $\mathrm{CB}[7]$. The limiting chemical shift changes, for the guest protons on weaker binding guests, were determined by extrapolation in fitting the chemical shift titrations.

\section{Results and discussion}

The ${ }^{1} \mathrm{H}$ NMR titrations of the Good's buffers with $\mathrm{CB}[7]$ (Fig. 2) provide a measurement of the host-guest stability constants (Table 1) and the limiting complexation-induced chemical shift changes for the guest proton resonances $\left(\Delta \delta_{\text {lim }}=\delta_{\text {bound }}-\delta_{\text {free }}\right)$ give an indication of the average position of the guest within the

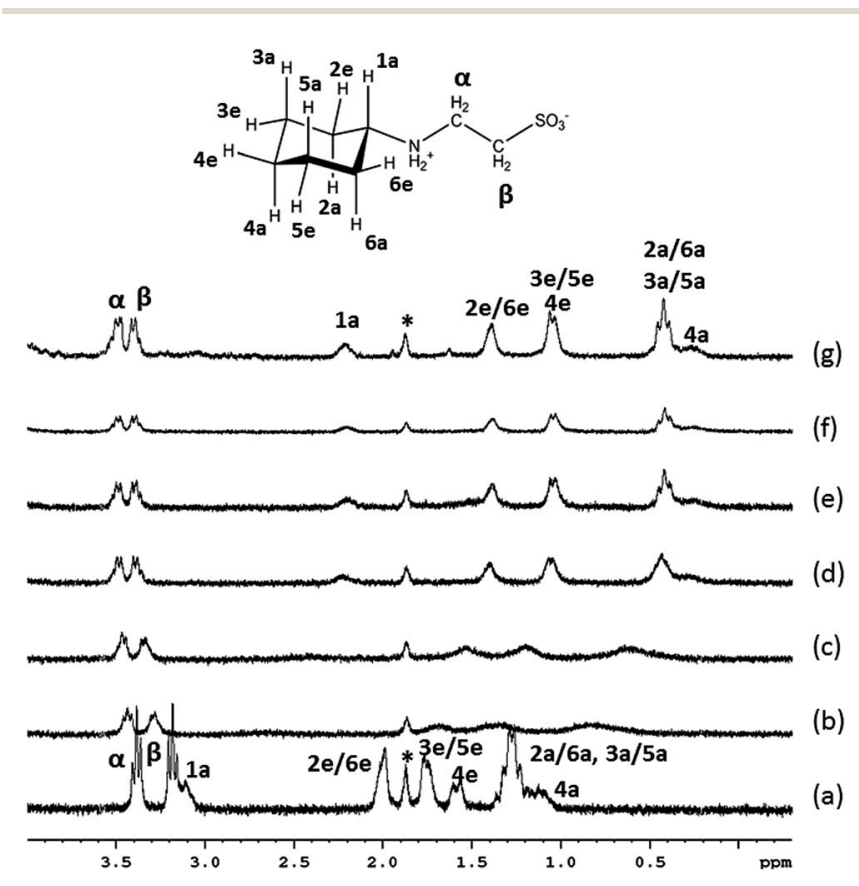

Fig. $2{ }^{1} \mathrm{H}$ NMR titration of CHES with (a) 0.00 , (b) 0.57 , (c) 0.80 , (d) 0.96 , (e) 1.05 , (f), 1.73, and (g) 4.20 equivalents of $C B[7]$ in $\mathrm{D}_{2} \mathrm{O}$ $\left(\mathrm{pD}=4.75,0.050 \mathrm{~mol} \mathrm{dm}^{-3} \mathrm{NaOAc}-d_{3}\left(^{*}\right) / 0.025 \mathrm{~mol} \mathrm{dm}^{-3} \mathrm{DCl}\right)$. 
Table 1 Host-guest stability constants for CB[7] with the Good's buffers in $\mathrm{D}_{2} \mathrm{O}\left(\mathrm{pD}=4.75,0.050 \mathrm{~mol} \mathrm{dm}{ }^{-3} \mathrm{NaOAc}-d_{3} / 0.025 \mathrm{~mol}\right.$ $\left.\mathrm{dm}^{-3} \mathrm{DCl}\right)$

\begin{tabular}{llll}
\hline Buffer & $\mathrm{p} K_{\mathrm{a}}$ & $\Delta \delta_{\lim }\left(H_{\alpha}\right), \mathrm{ppm}$ & $K_{\mathrm{CB}[7]}, \mathrm{dm}^{3} \mathrm{~mol}^{-1}$ \\
\hline HEPES & $7.55^{a}$ & +0.43 & $(2.3 \pm 0.3) \times 10^{3}$ \\
EPPS & $8.0^{b}$ & +0.27 & $(8.9 \pm 1.3) \times 10^{3}$ \\
HEPBS & $8.3^{b}$ & +0.04 & $(2.1 \pm 0.4) \times 10^{4}$ \\
PIPES & $2.67,6.78^{c}$ & 0 & 0 \\
PIPPS & $3.79,7.97^{c}$ & 0 & 0 \\
PIPBS & $4.29,8.55^{c}$ & +0.15 & $(2.2 \pm 0.6) \times 10^{3}$ \\
MES & $6.06^{c}$ & -0.02 & $210 \pm 30$ \\
MOPSO & $6.95^{d}$ & $-0.19,-0.32$ & $330 \pm 50$ \\
MOPS & $7.09^{c}$ & -0.25 & $(2.2 \pm 0.3) \times 10^{3}$ \\
MOBS & $7.48^{c}$ & -0.40 & $(2.4 \pm 0.3) \times 10^{3}$ \\
MeMOBS & & -1.05 & $(4.2 \pm 0.6) \times 10^{4}$ \\
CHES & $9.27^{e}$ & +0.10 & $(3.6 \pm 0.5) \times 10^{7}$ \\
CAPSO & $9.6^{f}$ & $+0.02,+0.13$ & $(6.0 \pm 0.9) \times 10^{7}$ \\
CAPS & $10.35^{e}$ & -0.02 & $(1.0 \pm 0.2) \times 10^{8}$ \\
CABS & $10.7^{b}$ & +0.03 & $(1.3 \pm 0.2) \times 10^{8}$ \\
TRIS & $8.06^{a}$ & & $290 \pm 50$ \\
TAPS & $8.4^{g}$ & -0.01 & $110 \pm 20$
\end{tabular}

${ }^{a}$ Ref. 58. ${ }^{b}$ Ref. $4 .{ }^{c}$ Ref. 27. ${ }^{d}$ Ref. $3 .{ }^{e}$ Ref. 59. ${ }^{f}$ Ref. $60 .{ }^{g}$ Ref. 61.

$\mathrm{CB}[7]$ cavity (Fig. $3, \mathrm{~S} 1, \mathrm{~S} 9, \mathrm{~S} 20 \dagger)$. Upfield shifts $\left(\Delta \delta_{\lim }<0 \mathrm{ppm}\right)$ for the proton resonances indicate positioning within the cavity, while downfield shifts are indicative of the protons located outside of the cavity near the polar portal(s) of $\mathrm{CB}[7]$. In the buffers which bind to the $\mathrm{CB}[7]$ in this study, the values of $\Delta \delta_{\text {lim }}$ (Fig. 3, S1, S9, S20†) indicate that the host is binding primarily over the ring (and the hydroxyethyl group for HEPES, EPPS, and HEPBS, Fig. 3 and $\mathrm{S} 20 \dagger$ ), rather than the alkylsulfonate chain.

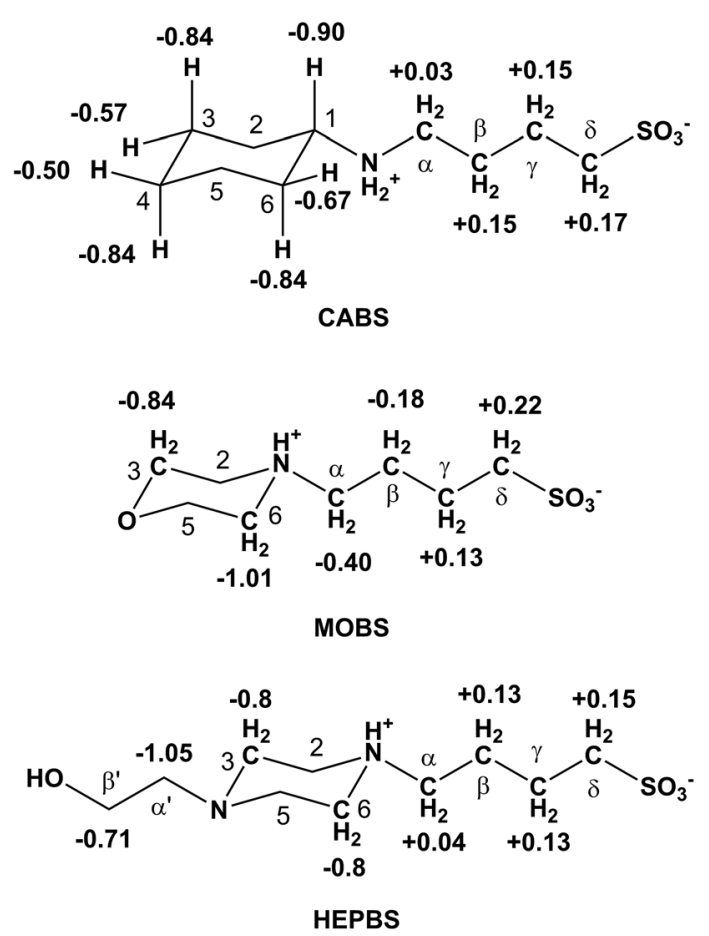

Fig. 3 CB[7] complexation-induced chemical shift changes, $\Delta \delta_{\text {lim }}(\mathrm{ppm})$, for representative buffers.
The strongest binding by $\mathrm{CB}[7]$ was observed for the cyclohexylammonium buffers (Fig. 2, S1-S8 $\dagger$ ), with stability constants in the range of $10^{7}$ to $10^{8} \mathrm{dm}^{3} \mathrm{~mol}^{-1}$ (Table 1). It is known that the cyclohexylammonium cation binds strongly to cucurbit[7]uril, as a result of the hydrophobic interactions of the cyclohexyl ring with the cavity of $\mathrm{CB}[7]$ and the ion-dipole interactions of the ammonium group at the carbonyl portal. Values of $K_{\mathrm{CB}[7]}=(2.4 \pm 0.4) \times 10^{7} \mathrm{dm}^{3} \mathrm{~mol}^{-1}\left(0.10 \mathrm{~mol} \mathrm{dm}^{-3}\right.$ $\left.\mathrm{Na}_{3} \mathrm{PO}_{4} / \mathrm{DCl}, \mathrm{pH}=7.4\right)$ and $1.1 \times 10^{8} \mathrm{dm}^{3} \mathrm{~mol}^{-1}(0.050 \mathrm{~mol}$ $\left.\mathrm{dm}^{-3} \mathrm{NaOAc}, \mathrm{pH} 4.0\right)$ been reported by Cao and Isaacs, ${ }^{62}$ and $\mathrm{Li}$ and Kaifer, ${ }^{63}$ respectively. Yu et al. have reported a value of $(3.1 \pm 0.1) \times 10^{6} \mathrm{dm}^{3} \mathrm{~mol}^{-1}\left(30^{\circ} \mathrm{C}, \mathrm{pH}=4.0\right)$ from an ITC experiment. ${ }^{64} \mathrm{Cao}$ and Isaacs have also observed that increasing the size of the ring in cycloalkylammonium cations increases the value of $K_{\mathrm{CB}[7]},{ }^{62}$ while Yu et al. observed a slight increase in the binding constant with the $N$-methylcyclohexylammonium cation. ${ }^{64}$ The introduction of a hydroxyl group on the $\beta$-carbon in CAPSO results in a slight reduction in the binding constant compared to CAPS.

The values of $K_{\mathrm{CB}[7]}$ increase with an increase in the number of methylene groups between the protonated nitrogen and the sulfonate group (Table 1). This would reduce the repulsions between the sulfonate group and the polar carbonyl groups on the $\mathrm{CB}[7]$ portal and increase the hydrophobicity of the guest.

The morpholinium buffers (MES, MOPS, MOPSO, and MOBS) exhibit lower binding constants than the corresponding cyclohexylammonium buffers (Table 1 ), with $K_{\mathrm{CB}[7]}$ in the range of 200-2400 dm $\mathrm{dm}^{3} \mathrm{~mol}^{-1}$, increasing with an increase in the alkylsulfonate chain length (Fig. 4, 5 and S10-S17†). This trend in higher $K_{\mathrm{CB}[7]}$ values is also accompanied by a deeper inclusion of the morpholine ring within the cavity, as exhibited by the greater upfield chemical shifts of the methylene groups which are attached to the protonated nitrogen $\left(H_{\alpha}:-0.01\right.$, -0.23 , and -0.35 ppm for MES, MOPS, and MOBS, respectively (Fig. 3, S9 $\dagger$ )). The MOPSO buffer has a slightly lower binding constant than MOPS, similar to that seen for CAPSO compared with CAPS.

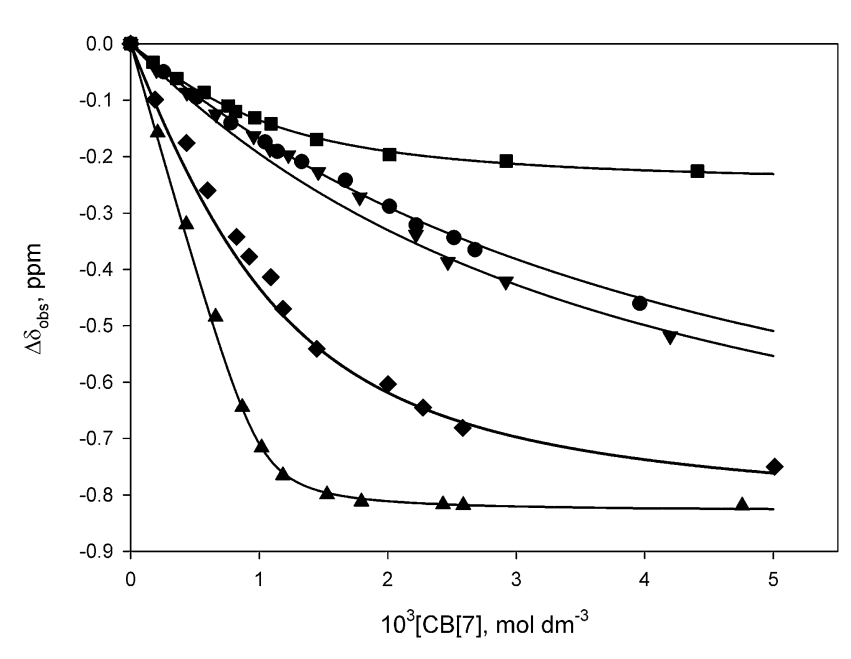

Fig. $4{ }^{1} \mathrm{H}$ NMR titrations of MES $\left(-\mathrm{H}_{3,5}\right)$, MOPS $\left(\boldsymbol{\square} \mathrm{H}_{3,5}\right)$, MOPSO $\left(\boldsymbol{\nabla} \mathrm{H}_{3,5}\right)$, MOBS $\left(\mathrm{H}_{3,5}\right)$, and MeMOBS $\left(\boldsymbol{\Delta} \mathrm{H}_{\mathrm{Me}}\right)$ with $\mathrm{CB}[7]$ in $\mathrm{D}_{2} \mathrm{O}$ $\left(\mathrm{pD}=4.75,0.050 \mathrm{~mol} \mathrm{dm}^{-3} \mathrm{NaOAc}-d_{3} / 0.025 \mathrm{~mol} \mathrm{dm}^{-3} \mathrm{DCl}\right)$. 


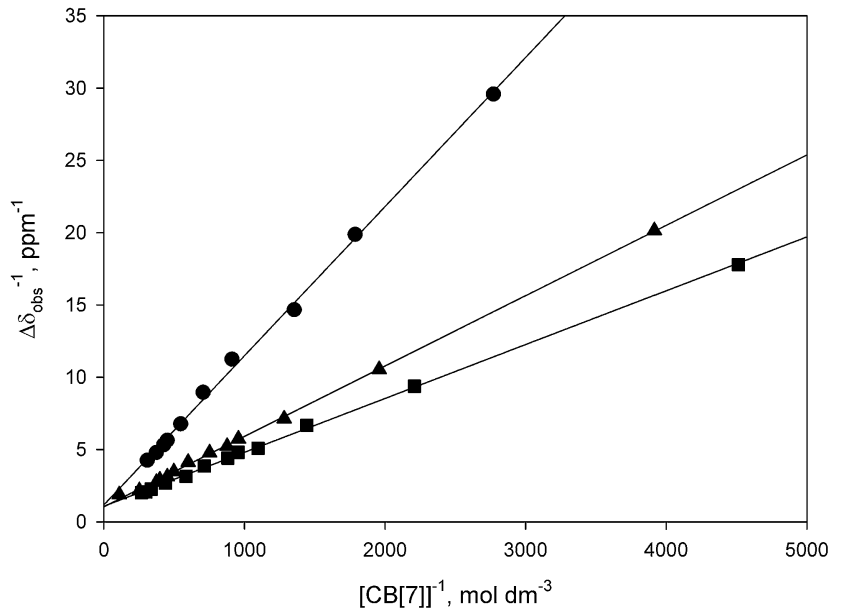

Fig. 5 Benesi-Hildebrand plots for the binding of TRIS ( $)$, TAPS ( $\square$ ), and $\operatorname{MES}(\mathbf{\Delta})$ with $\mathrm{CB}[7]$ in $\mathrm{D}_{2} \mathrm{O}\left(\mathrm{pD}=4.75,0.050 \mathrm{~mol} \mathrm{dm}^{-3} \mathrm{NaOAc}-\right.$ $\left.d_{3}(*) / 0.025 \mathrm{~mol} \mathrm{dm}^{-3} \mathrm{DCl}\right)$

Among the other zwitterionic guests investigated previously with $\mathrm{CB}[7]$, is carnitine which has also has a $\beta$-hydroxypropyl chain separating a trimethylammonium group (resides inside the $\mathrm{CB}[7]$ cavity) from a carboxylate group. ${ }^{65}$ The binding constant of $K_{\mathrm{CB}[7]}=8.0 \times 10^{4} \mathrm{dm}^{3} \mathrm{~mol}^{-1}$ for carnitine is between the values observed for MOPSO and CAPSO.

The $N$-methyl derivative of MOBS (MeMOBS) exhibited a higher binding constant of $(4.2 \pm 0.5) \times 10^{4} \mathrm{dm}^{3} \mathrm{~mol}^{-1}$, a factor of 20 compared to that of MOBS, with a very large upfield shift of -1.05 ppm for $H_{\alpha}$ (Fig. S19 and S20†). We have reported a similar increase in $\mathrm{CB}$ [7] binding of the zwitterionic $N^{\varepsilon}, N^{\varepsilon}, N^{\varepsilon}$-trimethyllysine $\left(6.0 \times 10^{4} \mathrm{dm}^{3} \mathrm{~mol}^{-1}\right)$ compared with protonated dimethyllysine $\left(2.1 \times 10^{3} \mathrm{dm}^{3} \mathrm{~mol}^{-1}\right) .{ }^{66}$ In both sets of guests, the replacement of a proton by a methyl group makes the ammonium center more hydrophobic and more included within the $\mathrm{CB}[7]$ cavity, as reflected in the values of $\Delta \delta_{\text {lim }}$.

The host-guest stability constants for this group of buffers are much lower than reported for protonated or alkylated morpholine guest molecules with $\mathrm{CB}[7]$, with $K_{\mathrm{CB}[7]}=(2.3 \pm 0.4)$ $\times 10^{6}$ and $(5.1 \pm 0.8) \times 10^{6} \mathrm{dm}^{3} \mathrm{~mol}^{-1}$ for the protonated $N$-methylmorpholine and $N, N$-dimethylmorpholinium, respectively. ${ }^{67}$ The sulfonate group on the alkyl substituent of the morpholinium buffers is likely responsible for their weaker binding to $\mathrm{CB}[7]$.

In the piperazinium family of buffers (HEPES, EPPS, and HEPBS), there is hydroxyethyl substituent on one of the $\mathrm{N}$ atoms, in addition to the alkylsulfonate substituents found in the cyclohexylammonium and morpholinium buffers. As with the other two sets of buffers, the magnitude of $K_{\mathrm{CB}[7]}$ (Table 1, Fig. S20-S26†) increases with alkylsulfonate chain length, with values about an order of magnitude greater than the corresponding morpholinium buffers. Either $\mathrm{N}$ atom could be the site of protonation of these buffers in slightly acidic solution, and for HEPES, both protonation tautomers have been observed in the solid state. ${ }^{68-70}$ Upon complexation by $\mathrm{CB}[7]$, the large upfield shifts in the hydroxyethyl proton resonances is suggestive of inclusion of this group and the piperazine ring within the host cavity, with the protonated nitrogen in proximity to one of the portals. The $\Delta \delta_{\text {lim }}$ values for the $H_{\alpha^{\prime}}$ and $H_{\alpha}$ resonances for HEPES and EPPS are larger in magnitude than normally seen for fully included guest protons (Fig. S20 $\dagger$ ). The chemical shift change for $H_{\alpha^{\prime}}$ is likely a combination of the shielding within the cavity plus an upfield shift as the buffer transitions between a tautomer equilibrium to a localized protonation on the $\mathrm{N}$ atom bearing the alkylsulfonate group. For the $H_{\alpha}$ resonance, this would lead to a greater downfield shift than strictly from deshielding effects of the $\mathrm{CB}[7]$ portal. The similarities in the resonance positions for the alkylsulfonate methylene protons, for the piperazinium buffers compared with those of the other two sets, suggests that the nitrogen bearing the alkylsulfonate group is the site of protonation on the complexed buffer. The piperazinium ring proton resonances become very broad (and difficult to locate) upon complexation (Fig. S21, S23, S25†), as the ring flipping rate approaches the NMR timescale. ${ }^{67}$

The replacement of the hydroxyethyl group on the aforementioned piperazinium buffers with another alkylsulfonate group gives rise to the diprotic bases PIPES, PIPPS, and PIPBS. With PIPES and PIPPS, no change in the guest proton resonances are observed upon addition of 5-fold $\mathrm{CB}[7]$ at low $\mathrm{pH}(\mathrm{pH}$ 1-2, both $\mathrm{N}$ atoms protonated), $\mathrm{pH} 5$ (one $\mathrm{N}$ atom protonated), and high $\mathrm{pH}$ (pH 11-12, both $\mathrm{N}$ atoms nonprotonated) (Fig. S27 and $\mathrm{S} 28 \dagger$ ). The formation of a host-guest complex would require the host to pass over one of the sulfonate groups to bind to the central piperazinium group. This, combined with the presence of repulsive sulfonate groups near each of the two CB [7] polar portals, would not provide for very stable internal hostguest ("pseudorotaxane") complexes. With PIPBS, the longer alkyl chains would reduce the ion-dipole repulsions, and changes in the guest proton resonances upon addition of $\mathrm{CB}$ [7] (Fig. S29†), with slow exchange behaviour, are observed for both the buffer and $\mathrm{CB}[7]$ proton resonances. A binding constant of $2.2 \times 10^{3} \mathrm{dm}^{3} \mathrm{~mol}^{-1}$ for PIPBS was determined using the integrations of the free and bound methine proton resonances.

The tris(hydroxymethyl)methylammonium buffers TRIS and TAPS bind weakly to CB[7] (Table 1, Fig. 5, S30-S33†), with TAPS exhibiting a lower binding constant as a result of the pendant $N$ ethylsulfonate group. The binding constants were determined by Benesi-Hildebrand plots using the methylene proton resonance of the hydroxymethyl groups (Fig. 5). The methylene proton resonances for the encapsulated hydroxymethyl arms of TRIS and TAPS shift upfield by -0.92 and $-0.85 \mathrm{ppm}$, respectively, while the ethylsulfonate group of the latter buffer remains outside the cavity of $\mathrm{CB}[7]$.

\section{pK $K_{\text {a }}$ shift of CHES}

The complexation of acidic guest molecules by cucurb[7]uril is known to increase the guest $\mathrm{p} K_{\mathrm{a}}$ value compared to that of the free acid. A pH titration of the $\mathrm{CB}[7]$-complexed CHES buffer $\left(\mathrm{p} K_{\mathrm{a}}\right.$ of free CHES is 9.27) ${ }^{58}$ was carried out in basic solution (Fig. 6). The $\mathrm{p} K_{\mathrm{a}}$ of the bound CHES was found to be 12.37, representing an increase of 3.1 units, as the deprotonation of the quaternary nitrogen results in weaker binding to the anionic guest species. This may be compared to a shift of $1.3 \mathrm{p} K_{\mathrm{a}}$ units 


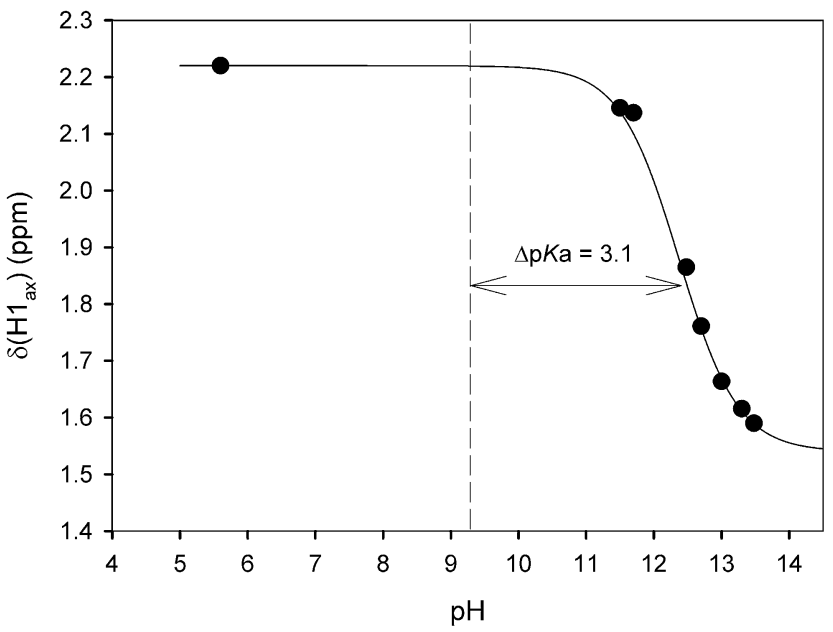

Fig. $6 \mathrm{pH}$ titration of the chemical shift of the CB[7] complex of CHES The dashed vertical line represents the $\mathrm{p} K_{\mathrm{a}}$ of free CHES.

for cyclohexylmethylamine upon binding to $\mathrm{CB}[6] .^{71}$ The larger shift for CHES with $\mathrm{CB}[7]$ would be consistent with a greater reduction in the binding of the conjugate base, because of the sulfonate group. The $\Delta \mathrm{p} K_{\mathrm{a}}$ value of 3.1 for CHES allows for a binding constant estimation $\left(K_{\mathrm{CB}[7]}^{\mathrm{b}}=K_{\mathrm{CB}[7]}^{\mathrm{a}}\left(10^{-\Delta \mathrm{p} K_{\mathrm{a}}}\right)\right)^{38,39}$ of $K_{\mathrm{CB}[7]}^{\mathrm{b}}=3 \times 10^{4} \mathrm{dm}^{3} \mathrm{~mol}^{-1}$ for the conjugate base of CHES. The binding constant for this form of CHES with the $\beta$-cyclodextrin $(\beta-\mathrm{CD})$ host has been reported to be $490 \pm 20 \mathrm{dm}^{3} \mathrm{~mol}^{-1}$ (pH 10.5 , with a similar value for CAPS) ${ }^{28}$ and $440 \pm 30 \mathrm{dm}^{3} \mathrm{~mol}^{-1}$ (pH 11.6). ${ }^{29}$ The zwitterionic form of CHES binds very much weaker (about $30 \mathrm{dm}^{3} \mathrm{~mol}^{-1}$ ) with $\beta$-CD, which would arise from a decrease in the $\mathrm{p} K_{\mathrm{a}}$ value upon complexation. ${ }^{29}$ The strong binding of the cyclohexylammonium buffers to $\mathrm{CB}[7]$, along with significant $\mathrm{p} K_{\mathrm{a}}$ shifts, would make them inappropriate as biological pH buffers with cucurbit[7]uril.

\section{Conclusions}

The macrocyclic host molecule cucurbit[7]uril exhibits a wide range of binding constants with the Good's biological $\mathrm{pH}$ buffers in aqueous solution. The $\mathrm{CB}[7]$ binding constants are observed to increase as the anionic sulfonate group is placed further from the protonated nitrogen site. The morpholinium (MES, MOPS, MOPSO) and tris(hydroxymethyl)methylammonium (TRIS, TAPS) buffers exhibit binding constants of $<10^{3} \mathrm{dm}^{3} \mathrm{~mol}^{-1}$ and could be used in studies with guests which exhibit significantly stronger binding with $\mathrm{CB}[7]$. We are presently looking at reducing the $\mathrm{CB}[7]$ binding strength by changing the alkyl spacer between the nitrogen and sulfonate groups to methane. ${ }^{72}$ The dibasic PIPES and PIPBS buffers would be useful for buffering biological $\mathrm{CB}[7]$ solutions over a wide $\mathrm{pH}$ range as internal $\mathrm{pH}$ indicators for ${ }^{1} \mathrm{H}$ NMR spectroscopy ${ }^{73}$ with $\mathrm{CB}[7]$. A mixture of PIPES ( $\mathrm{p} K_{\mathrm{a} 1}=2.67$ and $\mathrm{p} K_{\mathrm{a} 2}$ $=6.78)$ and acetic acid $\left(\mathrm{p} K_{\mathrm{a}}=4.75\right)$ would cover a significant $\mathrm{pH}$ range, and we are currently utilizing them in determining $\mathrm{p} K_{\mathrm{a}}$ shifts of polyprotic drug molecules upon complexation by $\mathrm{CB}[7]$.

\section{Conflicts of interest}

There are no conflicts to declare.

\section{Acknowledgements}

The financial support of this research by the Natural Sciences and Engineering Research Council of Canada, in the form of a Discovery Grant, is gratefully acknowledged.

\section{Notes and references}

1 N. E. Good, G. D. Winget, W. Winter, T. N. Connolly, S. Izawa and R. M. M. Singh, Biochemistry, 1966, 5, 497.

2 N. E. Good and S. Izawa, Methods Enzymol., 1972, 24, 53.

3 W. J. Ferguson, K. I. Braunschweiger, W. R. Braunschweiger, J. R. Smith, J. J. McCormick, C. C. Wasmann, N. P. Jarvis, D. H. Bell and N. E. Good, Anal. Biochem., 1980, 104, 300.

4 T. Thiel, L. Liczkowski and S. T. Bissen, J. Biochem. Biophys. Methods, 1998, 37, 117.

5 M. Taha, F. A. e. Silva, M. V. Quental, S. P. M. Ventura, M. G. Freire and J. A. P. Coutinho, Green Chem., 2014, 16, 3149.

6 M. Taha, M. R. Almeida, F. A. e. Silva, P. Domingues, S. P. M. Ventura, J. A. P. Coutinho and M. G. Freire, Chem.-Eur. J., 2015, 21, 4781.

7 S. Y. Lee, F. A. Vicente, F. A. e. Silva, T. E. Sintra, M. Taha, I. Khoiroh, J. A. P. Coutinho, P. L. Show and S. P. M. Ventura, ACS Sustainable Chem. Eng., 2015, 3, 3420. 8 B. S. Gupta, M. Taha and M.-J. Lee, RSC Adv., 2015, 5, 106764. 9 B. S. Gupta, M. Taha and M.-J. Lee, $R S C A d v .$, 2016, 6, 18567. 10 M. Taha, M. V. Quental, F. A. e Silva, E. V. Capela, M. G. Freire, S. P. M. Ventura and J. A. P. Coutinho, J. Chem. Technol. Biotechnol., 2017, 92, 2287.

11 A. Habib, M. Tabata and Y. G. Wu, Bull. Chem. Soc. Jpn., 2005, 78, 262.

12 J. Xie, J. Y. Lee and D. I. C. Wang, Chem. Mater., 2007, 19, 2823.

13 R. K. Gupta, V. Kumar, A. Srivastava and D. S. Pandey, RSC $A d v .$, 2016, 6, 40911.

14 C. Engelbrekt, M. Wagner, M. U.-B. Christiansen, H. E. M. Christensen, X. Qian, J. Ulstrup, C. Zhao and J. Zhang, ChemElectroChem, 2016, 3, 1212.

15 K. Chandra, K. S. B. Culver, S. E. Werner, R. C. Lee and T. W. Odom, Chem. Mater., 2016, 28, 6763.

16 E. R. Clark and D. M. Kurtz Jr, Inorg. Chem., 2017, 56, 4584. 17 J. M. Pope, P. R. Stevens, M. T. Angotti and R. Nakon, Anal. Biochem., 1980, 103, 214.

18 R. Nakon and C. R. Krishnamoorthy, Science, 1983, 221, 749. 19 H. A. Azab, F. S. Deghaidy, A. S. Orabi and N. Y. Farid, J. Chem. Eng. Data, 2000, 45, 709.

20 M. Sokołowska and W. Bal, J. Inorg. Biochem., 2005, 99, 1653. 21 M. Taha, R. A. Saqr and A. T. Ahmed, J. Chem. Thermodyn., 2007, 39, 304.

22 Z. M. Anwar and H. A. Azab, J. Chem. Eng. Data, 2011, 46, 34. 23 C. M. H. Ferreira, I. S. S. Pinto, E. V. Soares and H. M. V. M. Soares, RSC Adv., 2015, 5, 30989. 
24 S. O. Ugwu and S. P. Apte, Pharm. Technol., 2004, 28, 86.

25 B. S. Gupta, M. Taha and M.-J. Lee, Phys. Chem. Chem. Phys., 2015, 17, 1114.

26 Q. Yu, A. Kandegedara, Y. Xu and D. B. Rorabacher, Anal. Biochem., 1997, 253, 50.

27 A. Kandegedara and D. B. Rorabacher, Anal. Chem., 1999, 71, 3140.

28 M. E. Georgiou, C. A. Georgiou and M. A. Kouppans, Anal. Chem., 1995, 67, 114.

29 M. Riesová, J. Svobodová, Z. Tošner, M. Beně̌, E. Tesařová and B. Gaš, Anal. Chem., 2013, 85, 8518.

30 M. Beneš, M. Riesová, J. Svobodová, E. Tesařová, P. Dubský and B. Gaš, Anal. Chem., 2013, 85, 8526.

31 M. E. Davis and M. E. Brewster, Nat. Rev. Drug Discovery, 2004, 3, 1023.

32 C. Adeoye and H. Cabral-Marques, Int. J. Pharm., 2017, DOI: 10.1016/j.ijpharm.2017.04.050.

33 F. Perret and A. W. Coleman, Chem. Commun., 2011, 47, 7303.

34 E. Masson, X. Ling, R. Joseph, L. Kyeremeh-Mensah and X. Lu, RSC Adv., 2012, 2, 1213.

35 S. J. Barrow, S. Kasera, M. J. Rowland, J. del Barrio and O. A. Scherman, Chem. Rev., 2015, 115, 12320.

36 K. I. Assaf and W. M. Nau, Chem. Soc. Rev., 2015, 44, 394.

37 L. Cao, M. Šekutor, P. Y. Zavalij, K. Mlinarić-Majerski, R. Glaser and L. Isaacs, Angew. Chem., Int. Ed., 2014, 53, 988.

38 D. H. Macartney, Isr. J. Chem., 2011, 51, 600.

39 I. Ghosh and W. M. Nau, Adv. Drug Delivery, 2012, 64, 764.

40 D. H. Macartney, Future Med. Chem., 2013, 5, 2075.

41 K. I. Kuok, S. Li, I. W. Wyman and R. Wang, Ann. N. Y. Acad. Sci., 2017, 1398, 108.

42 G. Hettiarachchi, D. Nguyen, J. Wu, D. Lucas, L. Isaacs and V. Briken, PLoS One, 2010, 5, e10514.

43 V. D. Uzunova, C. Cullinane, K. Brix and W. M. Nau, Org. Biomol. Chem., 2010, 8, 2037.

44 R. Oun, R. S. Floriano, L. Isaacs, E. G. Rowan and N. J. Wheate, Toxicol. Res., 2014, 3, 447.

45 H. Chen, J. Y. Chan and X. Yang, RSC Adv., 2015, 5, 30067.

46 H.-J. Kim, W. S. Jeon, Y. H. Ko and K. Kim, Proc. Natl. Acad. Sci. U. S. A., 2002, 99, 5007.

47 W. Ong and A. E. Kaifer, J. Org. Chem., 2004, 69, 1383.

48 Y. J. Jeon, S.-Y. Kim, Y. H. Ko, S. Sakamoto, K. Yamaguchi and K. Kim, Org. Biomol. Chem., 2005, 3, 2122.

49 N. Barooah, A. Kunwar, R. Khurana, A. C. Bhasikuttan and J. Mohanty, Chem.-Asian J., 2017, 12, 122.
50 T. Tian, Y. Song, L. Wei, J. Wang, B. Fu, Z. He, X.-R. Yang, F. Wu, G. Xu, S.-M. Liu, C. Li, S. Wang and X. Zhou, Nucleic Acids Res., 2017, 45, 2283.

51 I. W. Wyman and D. H. Macartney, Org. Biomol. Chem., 2008, 6, 1796.

52 H. Tang, D. Fuentealba, Y. H. Ko, N. Selvapalam, K. Kim and C. Bohne, J. Am. Chem. Soc., 2011, 133, 20623.

53 A. Day, A. P. Arnold, R. J. Blanch and B. Snushall, J. Org. Chem., 2001, 66, 8094.

54 F. Yi, J. Gao, L. Zhang and X. Jiang, Asian J. Chem., 2015, 27, 1260.

55 M. A. Jermyn, Aust. J. Chem., 1967, 20, 183.

56 S. Liu, C. Ruspic, P. Mukhopadhyay, S. Chakrabarti, P. Y. Zavalij and L. Isaacs, J. Am. Chem. Soc., 2005, 127, 15959.

57 K. A. Connors, Binding Constants, Wiley-Interscience, Toronto, 1987.

58 J. C. Lewis, Anal. Biochem., 1966, 14, 495.

59 Y. Chen, L. Jing, X. Li and Y. Zhu, J. Chromatogr. A, 2006, 1118, 3.

60 Q. Liu, X. Li and S. S. Sommer, Anal. Biochem., 1999, 270, 112.

61 T. L. Esplin, M. L. Cable, H. B. Gray and A. Ponce, Inorg. Chem., 2010, 49, 4643.

62 L. Cao and L. Isaacs, Supramol. Chem., 2014, 26, 251.

63 W. Li and A. E. Kaifer, Organometallics, 2013, 32, 6091.

64 J.-S. Yu, F.-G. Wu, L.-F. Tao, J.-J. Luo and Z.-W. Yu, Phys. Chem. Chem. Phys., 2011, 13, 3638.

65 I. W. Wyman and D. H. Macartney, Org. Biomol. Chem., 2010, 8, 253.

66 M. A. Gamal-Eldin and D. H. Macartney, Org. Biomol. Chem., 2013, 11, 488.

67 M. A. Gamal-Eldin and D. H. Macartney, Org. Biomol. Chem., 2013, 11, 1234.

68 J. Wouters and D. Stalke, Acta Crystallogr., Sect. C: Cryst. Struct. Commun., 1966, 52, 1684.

69 P. Śledź, T. Minor and M. Chruszcz, Acta Crystallogr., Sect. E: Struct. Rep. Online, 2009, 65, o3027.

70 P. Śledź, R. Kamiński, M. Chruszcz, M. D. Zimmerman, W. Minor and K. Woźniak, Acta Crystallogr., Sect. B: Struct. Sci., 2010, 66, 482.

71 C. Marquez and W. M. Nau, Angew. Chem., Int. Ed., 2011, 40, 3155.

72 R. D. Long, N. P. Hilliard Jr, S. A. Chhatre, T. V. Timofeeva, A. A. Yakovenko, D. K. Dei and E. A. Mensay, Beilstein J. Org. Chem., 2010, 6, 31.

73 Z. Szakács, G. Hägelea and R. Tyka, Anal. Chim. Acta, 2004, 522, 247. 